\title{
Ligation of the T Cell Receptor Complex Results in Activation of the Ras/Raf-1/MEK/MAPK Cascade in Human T Lymphocytes
}

\author{
Richard A. Franklin, Attila Tordai, Hiren Patel, Anne M. Gardner, Gary L. Johnson, and Erwin W. Gelfand \\ Division of Basic Sciences, Department of Pediatrics, National Jewish Center for Immunology and Respiratory Medicine, Denver, \\ Colorado 80206
}

\begin{abstract}
Stimulation of $\mathbf{T}$ cells with antibodies directed towards the $\mathbf{T}$ cell receptor complex results in the activation of mitogen-associated protein kinase (MAPK). Two pathways have been described in other cell types that can lead to MAPK activation. One of these pathways involves the activation of Ras, leading to the activation of Raf-1, and the subsequent activation of MEK (MAPK or ERK kinase). The contribution of this pathway in $T$ cells for anti-CD3 or phorbol myristate acetate (PMA)-mediated MAPK activation was examined. We detected the kinase activities of Raf-1 and MEK towards their substrates (MEK for Raf-1 and MAPK for MEK) in this pathway leading to the activation of MAPK. Stimulation of the $T$ cells with either anti-CD3 antibody or PMA resulted in a rapid activation of both Ras and Raf-1. MEK activity towards kinase-active or -inactive recombinant MAPK also increased upon stimulation. In addition, both MAPK and $\mathbf{p 9 0}^{\text {rsk }}$ were activated in these cells. We suggest that activation of MAPK and the subsequent activation of ribosomal S6 kinase ( $\mathrm{p}^{\mathrm{9}}{ }^{\mathrm{rk}}$ ) occurs by the Ras/ Raf-1 /MEK cascade in T lymphocytes stimulated by ligation of the T cell receptor complex. (J. Clin. Invest. 1994. 93:21342140.) Key words: $T$ lymphocyte $\bullet$ cell signaling $\bullet$ kinase activation • kinase $\bullet$ mitogen-associated protein
\end{abstract}

\section{Introduction}

The $\mathrm{T}$ cell receptor is made up of multiple proteins that transduce a signal (antigen/MHC) received at the surface of the cell to the nucleus. There are multiple second messenger pathways activated after $\mathrm{T}$ cell receptor stimulation, including the triggering of calcium fluxes, activation of protein kinase $C$, and the induction of several tyrosine kinases (for review see references 1-5). These changes can then affect more downstream events, particularly the increased transcription of certain activation-related genes and cell proliferation (1-7). Several reports demonstrate that mitogen-associated protein kinase (MAPK) ${ }^{1}$ under-

R. A. Franklin and A. Tordai contributed equally to the work. Address correspondence to Erwin W. Gelfand, Division of Basic Sciences, Department of Pediatrics, National Jewish Center for Immunology and Respiratory Medicine, Denver, CO 80206.

Received for publication 1 November 1993 and in revised form 11 January 1994

1. Abbreviations used in this paper: EGFR, epidermal growth factor receptor peptide; KMMAPK, recombinant kinase-inactive mitogenassociated protein kinase; KMMEK, kinase-inactive MAPK or ERK kinase; MAPK, mitogen-associated protein kinase; MEK, MAPK or ERK kinase; PAS, protein A-Sepharose beads.

J. Clin. Invest.

(c) The American Society for Clinical Investigation, Inc 0021-9738/94/05/2134/07 \$2.00

Volume 93, May 1994, 2134-2140 goes tyrosine as well as threonine phosphorylation, which results in its activation after $T$ cell receptor stimulation (8-12). It is thought that MAPK, a serine/threonine kinase, is one of the intermediates in the transduction pathway leading to the increase in gene transcription and proliferation (13-16).

MEK (MAPK or ERK kinase), which lies directly upstream of MAPK in this cascade, has recently been characterized in several systems. This dual-specificity kinase is capable of activating MAPK and has been suggested to be a convergence point in the MAPK regulatory network (17-19). To date, two distinct mechanisms have been proposed to activate MEK (20-24). One pathway involves the Ras-dependent activation of Raf-1 kinase (21-24). The second pathway involves the activation of MEK kinase (20). Little is known about the regulation of MEK kinase except, like Raf-1, it is capable of activating MEK (20).

We determined if the Ras/Raf-1/MEK cascade has a role in anti-CD3-induced activation of MAPK in T lymphocytes. In addition, we demonstrated the ability of anti-CD3 to activate $\mathrm{p} 90^{\text {rsk }}$ since MAPK has the ability to phosphorylate and activate this important regulatory protein (25). After addition of either anti-CD3 or phorbol myristate acetate (PMA) we now report increases in Ras, Raf-1 kinase, and MEK activities. In addition, we show the concurrent activation of both MAPK and $\mathrm{p} 90^{\text {rsk }}$. We propose that Ras-dependent activation of Raf1 and MEK is responsible for the stimulation of MAPK and $\mathrm{p} 90^{\text {rsk }}$ in $\mathrm{T}$ cells activated by anti-CD3 or PMA.

\section{Methods}

Cells and reagents. The human $\mathrm{T}$ lymphocyte cell line Jurkat was obtained from American Type Culture Collection (Rockville, MD). The cells were maintained in RPMI 1640 (GIBCO, Grand Island, NY) supplemented with $10 \%$ FCS (Hyclone, Logan, UT), $50 \mathrm{U} / \mathrm{ml}$ penicillin-streptomycin, and $2 \mathrm{mM}$ glutamine at $37^{\circ} \mathrm{C}$ and $7 \% \mathrm{CO}_{2}$. AntiCD3 (OKT3) was obtained from Ortho Pharmaceutical Corp. (Rari$\tan , \mathrm{NJ}$ ); PMA, protein A-Sepharose beads (PAS), and purified rabbit $\mathrm{IgG}$ were purchased from Sigma Chemical Co. (St. Louis, MO). Monoclonal mouse anti-MAPK antibody was purchased from Zymed (South San Francisco, CA). Polyclonal rabbit anti-MEK antibody was obtained from Transduction Laboratories (Lexington, KY) and rabbit polyclonal anti-Raf-1 was purchased from Santa Cruz Biotechnology (Santa Cruz, CA). Affinity purified polyclonal rabbit anti-mouse rsk1 S6 kinase antibody was purchased from Upstate Biotechnology, Inc. (Lake Placid, NY). The recombinant wild-type and kinase-inactive forms of MEK and MAPK were expressed and purified as described (26).

Measurement of Raf-1 kinase activity. Measurement of Raf-1 kinase activity was performed as previously described $(26,27)$. Briefly, $1.2 \times 10^{7}$ Jurkat cells were stimulated in RPMI 1640 using the appropriate conditions. They were then lysed in RIPA ( $1 \%$ sodium deoxycholate, $1 \%$ Triton $\mathrm{X}-100,0.1 \%$ SDS, $150 \mathrm{mM} \mathrm{NaCl}, 50 \mathrm{mM}$ Tris ( $\mathrm{pH}$ 7.2), $1 \mathrm{mM}$ PMSF, $2 \mu \mathrm{g} / \mathrm{ml}$ aprotinin, $50 \mu \mathrm{M}$ leupeptin, $200 \mu \mathrm{M}$ $\mathrm{Na}_{3} \mathrm{VO}_{4}, 50 \mathrm{mM} \mathrm{NaF}$ ). Lysates were precleared by PAS beads and purified polyclonal anti-Raf-1 antibody (1:100) was added to the lysates. The immune complexes were collected by PAS beads and kinase 
assays were performed using kinase-inactive MEK (KMMEK) as a substrate. The purified recombinant KMMEK runs as a $50-\mathrm{kD}$ protein because of the six histidine tag and additional amino acids from the RSET expression vector (Invitrogen, La Jolla, CA). The proteins were separated by $10 \%$ SDS-PAGE and transferred to a nitrocellulose membrane. The membranes were probed using the same anti-Raf-1 antibody with an alkaline phosphatase visualization system (protoblot APsystem; Promega Biotec, Madison, WI) and subjected to autoradiography. Quantitation of ${ }^{32} \mathrm{P}$ incorporation into the recombinant kinase-inactive MEK was performed with a phosphor-imager (Molecular Dynamics, Sunnyvale, CA).

Measurement of Ras activation. Cells $\left(5 \times 10^{6}\right)$ were labeled with $\left.{ }^{32} \mathrm{P}\right]$ orthophosphate for $16 \mathrm{~h}$ before stimulation. Ras was immunoprecipitated using the Y13-259 anti-Ras antibody and GTP was separated from GDP by thin layer chromatography as previously described (28). The radiolabeled nucleotides were visualized by autoradiography and quantitated with a phosphor-imager. Data are presented as GTP/GTP + (1.5)GDP ratios (28).

MEK activity measurements. Measurements of MEK activity were performed as previously described $(26,27)$. After the different treatments, $4-5 \times 10^{7}$ cells were lysed in $600 \mu \mathrm{l}$ lysis buffer. After lysis, the samples were centrifuged and $500 \mu \mathrm{l}$ of the postnuclear cell lysates were fractionated on a mono-S HR 5/5 FPLC column (Pharmacia, Uppsala, Sweden). The fractions were assayed for kinase activity in a coupled system containing recombinant wild-type MAPK (ERK2, 42-kD polypeptide) and epidermal growth factor receptor peptide $\left(\right.$ EGFR $\left._{662-681}\right)(26,27)$. Simultaneously, some of the fractions were also assayed for their ability to phosphorylate recombinant, kinase-inactive MAPK (KMMAPK) $(26,27)$. Phosphorylated KMMAPK (which also runs as a $50-\mathrm{kD}$ protein) was separated on a $10 \%$ SDSPAGE gel and transferred onto nitrocellulose membranes. Phosphorylation of KMMAPK was then visualized by autoradiography and quantitated by phosphor-imager. The assay was performed using enzyme, substrate, and time so that the activity measured is linearly related to enzyme concentration.

Immunoblotting. After different treatments, $2.5 \times 10^{6}$ Jurkat cells were lysed in RIPA buffer and immunoblotted as previously described (29). Briefly, samples were electrophoresed through $10 \%$ SDS-PAGE gels and proteins were transferred to nitrocellulose membranes. Membranes were incubated $(2 \mathrm{~h})$ in blocking buffer; monoclonal antiMAPK $(1: 2,000)$ or anti-p90 ${ }^{\text {rsk }}(1: 10,000)$ were then added to the blocking buffer and blots were incubated for an additional $2 \mathrm{~h}$ at room temperature. The blots were washed in TBST ( $25 \mathrm{mM}$ Tris- $\mathrm{HCl}$ ( $\mathrm{pH}$ 8.0 ), $125 \mathrm{mM} \mathrm{NaCl}, 0.025 \%$ Tween 20 ) and incubated with alkaline phosphatase-conjugated goat anti-rabbit Ig (1:10,000 in TBST; Promega), for the anti-p90 ${ }^{\text {rsk }}$ blots, or alkaline phosphatase-conjugated goat anti-mouse $\operatorname{Ig}$ ( 1:10,000 in TBST; Promega) for the MAPK blots.

$p 90^{\text {rsk }}$ activity measurements. $\mathrm{p} 90$ ribosomal $\mathrm{S} 6$ kinase activity was detected as previously described $(30,31)$. Cells $\left(2.5 \times 10^{6}\right)$ were stimulated and $\mathrm{p} 90^{\text {rsk }}$ was immunoprecipitated from postnuclear lystes using polyclonal rabbit anti-mouse rsk 1 S6 kinase antibody (32) and protein A-protein $\mathrm{G}$ coupled beads. The beads were washed and resuspended in kinase buffer $(50 \mu \mathrm{l})$ containing $\gamma\left[{ }^{32} \mathrm{P}\right] \mathrm{ATP}$ and $125 \mu \mathrm{M}$ S6 peptide (RRRLSSLRA). Kinase reactions were incubated $\left(30^{\circ} \mathrm{C}\right.$ for $\left.15 \mathrm{~min}\right)$, stopped by the addition of EDTA, and the supernatant $(25 \mu \mathrm{l})$ was applied to filter paper (P81; Whatman Inc., Clifton, NJ). Filter papers were washed and radioactivity bound to the filter papers was determined by liquid scintillation counting. Parallel samples were immunoprecipitated in the same manner and resuspended in sample buffer and immunoblotted using the immunoprecipitating antibody. The assay was performed using enzyme, substrate, and time so that the activity measured is linearly related to enzyme concentration.

\section{Results and Discussion}

Two pathways leading to the activation of MAPK have been described in other cell types (20-24). We determined if the triggering of one of these pathways occurred after stimulation of $T$ cells through the T-cell receptor. Because of recent advances we were able to measure the specific kinase activity of Raf-1 towards a downstream substrate, $\operatorname{MEK}(20,26)$, in the proposed pathway, as well as measuring the ability of cellular MEK to phosphorylate and activate recombinant MAPK in activated $T$ cells. In this report we demonstrate the activation of the Ras/Raf- $1 / \mathrm{MEK} / \mathrm{MAPK} / \mathrm{p} 90^{\text {rsk }}$ pathway in $\mathrm{T}$ cells stimulated after ligation of the $\mathrm{T}$-cell receptor.

Activated Raf-1 kinase has been proposed to phosphorylate and activate MEK (21-24). A recombinant kinase inactive MEK (KMMEK) that lacks kinase and autophosphorylation activities because of mutation of lysine ${ }^{97}$ to methionine in the ATP binding site was recently developed $(26,27)$. This recombinant protein can be used as a substrate to measure the ability of Raf-1 to phosphorylate this enzyme. When Jurkat cells were stimulated with an antibody directed towards the CD3 complex, the activation of Raf-1 kinase activity (towards KMMEK) in these cells was rapid, detectable within $1 \mathrm{~min}$, and peaked at $\sim 2.5 \mathrm{~min}$ (Fig. $1 \mathrm{~A}$ ). The protein kinase $\mathrm{C}$ activator, PMA, was able to induce comparable levels of Raf-1 kinase activity. When immunoprecipitations were performed using nonspecific rabbit Ig to control for nonspecific interactions by the anti-Raf- 1 antibody, very little kinase activity was precipitated. Lane 1 in Fig. $1 A$ contains a cell-free sample of recombinant wild-type MEK (which has the capacity for autophosphorylation). This was used to locate the substrate (KMMEK) and control for the kinase reaction. Quantitation of the same experiment by phosphor-imager is shown in Fig. 1 $B$, revealing an $\sim 12$-fold increase in Raf-1 kinase activity 2.5 min after stimulation of Jurkat cells by anti-CD3. The PMAinduced stimulation of Raf- 1 was in a similar range, an $\sim 16$ fold increase $20 \mathrm{~min}$ after stimulation. To ensure that our antibody to Raf-1 kinase immunoprecipitated similar amounts of Raf- 1 under all treatment conditions, we used the same antibody to probe the immunoprecipitates used in the kinase assay (Fig. $1 C$ ). Besides the immunoglobulin bands, a single band ( Raf-1 ), was observed just below the $80-\mathrm{kD}$ marker. Raf-1 in the immunoprecipitates was somewhat variable, but the increased activity was clearly related to activation of the enzyme and not increased amounts of enzyme in the immunoprecipitate. No bands were observed when rabbit IgG was used for the immunoprecipitations (Fig. $1 C$, lane 9 ).

These data demonstrate that both anti-CD3 and PMA are able to induce the kinase activities of Raf- 1 towards MEK in T cells. The hyperphosphorylation and increased kinase activities of Raf- 1 after $\mathrm{T}$ cell receptor activation has been previously reported (33), however, this is the first report in $T$ cells that shows that Raf-1, immunoprecipitated from activated $T$ cells, is capable of phosphorylating another kinase (MEK) and participating in a signaling program.

In several systems, the Ras-dependent activation of Raf-1 has been described $(22-24,34)$. We measured the amounts of ${ }^{32} \mathrm{P}$-labeled GTP bound to Ras under the same stimulation conditions shown to induce high activities of Raf- 1 to assess Ras activation in our system. Fig. $2 A$ illustrates the GTP/GTP $+(1.5)$ GDP ratios associated with Ras in control, anti-CD3 (2.5 min), or PMA ( $10 \mathrm{~min}$ )-stimulated Jurkat cells. These ratios increased from $7 \%$ in the control cells, to $26 \%$, indicating the activation of Ras under these conditions in anti-CD3-stimulated Jurkat cells. In PMA-stimulated Jurkat cells, these levels increased to $34 \%$. We found that activation of Ras by anti-CD3 or PMA rapidly increased by $2.5 \mathrm{~min}$ and reached plateau lev- 


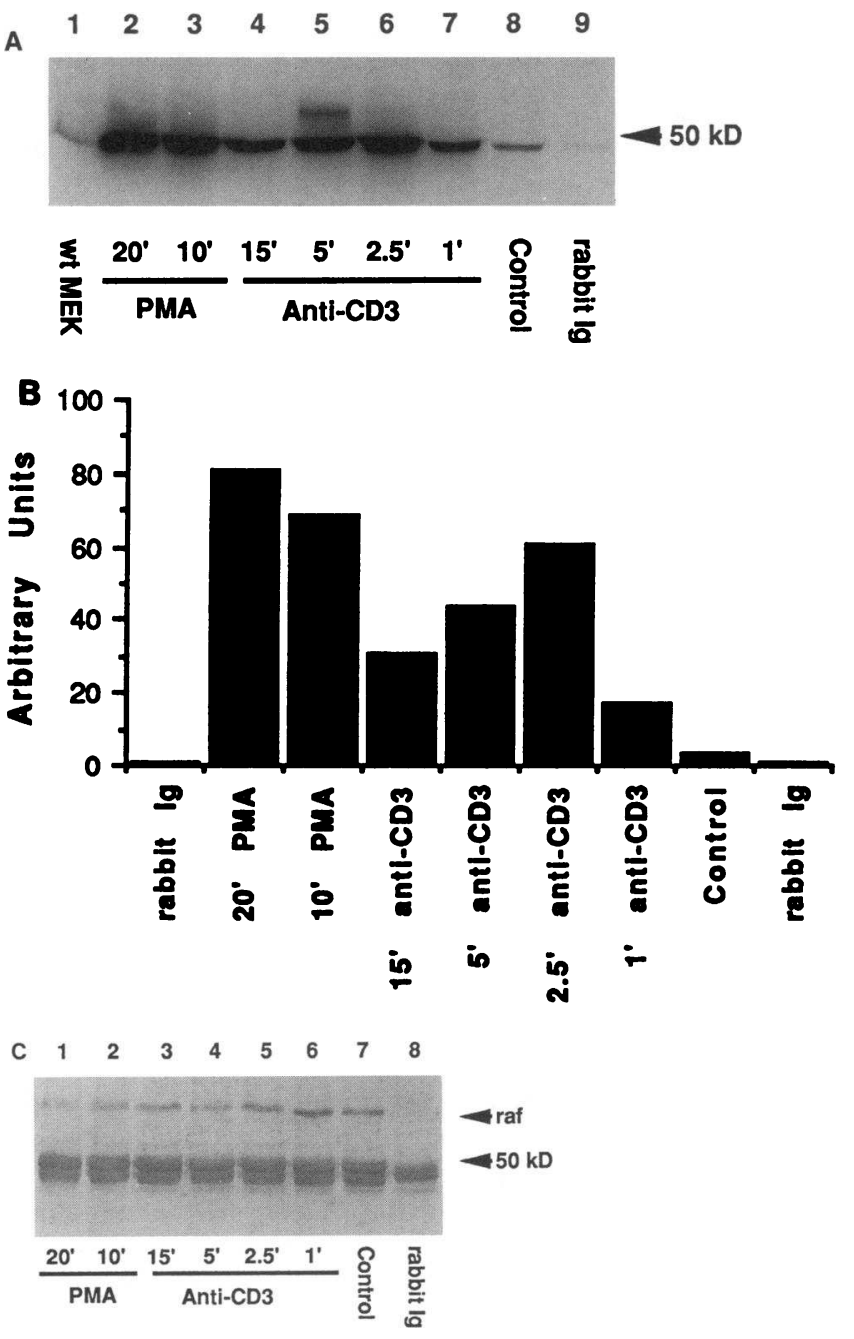

Figure 1. Activation of Raf-1 by anti-CD3 and PMA. For $A$ and $C$, Jurkat cells were treated with $1 \mu \mathrm{g} / \mathrm{ml}$ anti-CD3 antibody or $10 \mathrm{ng} / \mathrm{ml}$ PMA for the indicated times (in min); Raf-1 was immunoprecipitated and a kinase assay was performed as described in Methods. After SDS-PAGE, the proteins were transferred onto nitrocellulose. In $A$, ${ }^{32} \mathrm{P}$ incorporation into recombinant kinase-inactive MEK was measured by autoradiography. The lane marked wt MEK contained kinase active MEK and was used to locate the substrate. $(B){ }^{32} \mathrm{P}$ incorporation into kinase-inactive MEK in the same experiment was quantitated by a phosphor-imager and shown are the arbitrary unit values for the same conditions as in $A$. In $C$, the same membrane in $A$ was probed with the anti-Raf-1 antibody used for immunoprecipitation and reactivity was visualized by the alkaline phosphatase system. The size (in $\mathrm{kD}$ ) and the position of a molecular weight marker is indicated on the right side. In both $A$ and $C$, the lane marked rabbit Ig indicates when $0.6 \mu \mathrm{g}$ purified rabbit IgG was used for the immunoprecipitations as a control. Representative of at least two separate experiments.

els $\sim 10$ min after stimulation (Fig. $2 B$ ), paralleling the increases in Raf- 1 activation. These results are in agreement with those of Downward et al. (28) who have shown similar levels of Ras activation in PHA- and UCTH-1-stimulated Jurkat and HPB-ALL cells.

The phosphorylation and activation of MEK triggers the ability of MEK to phosphorylate and activate MAPK (17-19). To assess MEK activation in Jurkat cells stimulated by either
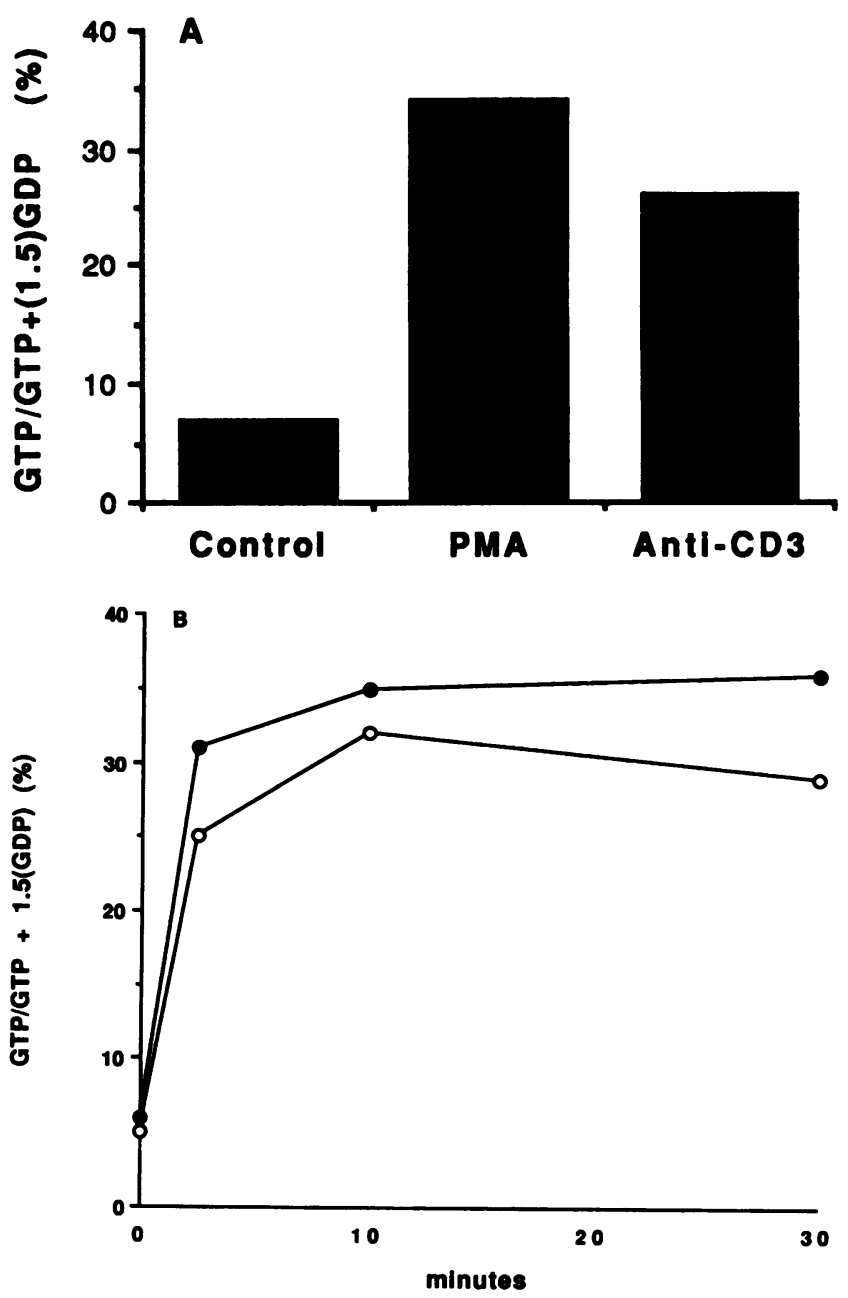

Figure 2. Stimulation of Ras activity by anti-CD3 and PMA. Metabolically labeled [ $\left.{ }^{32} \mathrm{P}\right]$ Jurkat cells were treated with $1 \mu \mathrm{g} / \mathrm{ml}$ anti-CD3 or with $10 \mathrm{ng} / \mathrm{ml}$ PMA for 2.5 and $10 \mathrm{~min}$, respectively, in $A$ or for the indicated periods of time in $B$. (Anti-CD3, open circles, PMA, closed circles.) Ras was immunoprecipitated, and radioactive GTP and GDP bound to Ras was measured by autoradiography. The data were quantitated by phosphor-imager and shown as the GTP/GTP $+(1.5)$ GDP ratios (\%) for each condition. The results are representative of three separate experiments.

PMA or anti-CD3, we used both a direct and indirect system. In both systems we fractionated lysates from Jurkat cells using fast phase liquid chromatography and a mono-S column. The proteins were eluted off the mono-S column using a salt gradient and the different fractions were examined for the ability to phosphorylate (direct method) or activate (indirect method) recombinant MAPK. The advantage of the direct method was that it enabled us to examine changes in the phosphorylation status of MAPK induced by the different fractions. The advantage of the indirect method was that it allowed examination of MAPK activity presumably induced by the changes in phosphorylation.

In the direct approach the fractions from the column were assessed for their ability to phosphorylate recombinant kinaseinactive MAPK (KMMAPK). Like KMMEK this protein has also lost the ability to autophosphorylate. Fig. $3 A$ shows the results of in vitro kinase assays followed by SDS-PAGE and autoradiography using the different fractions. Kinase activity 

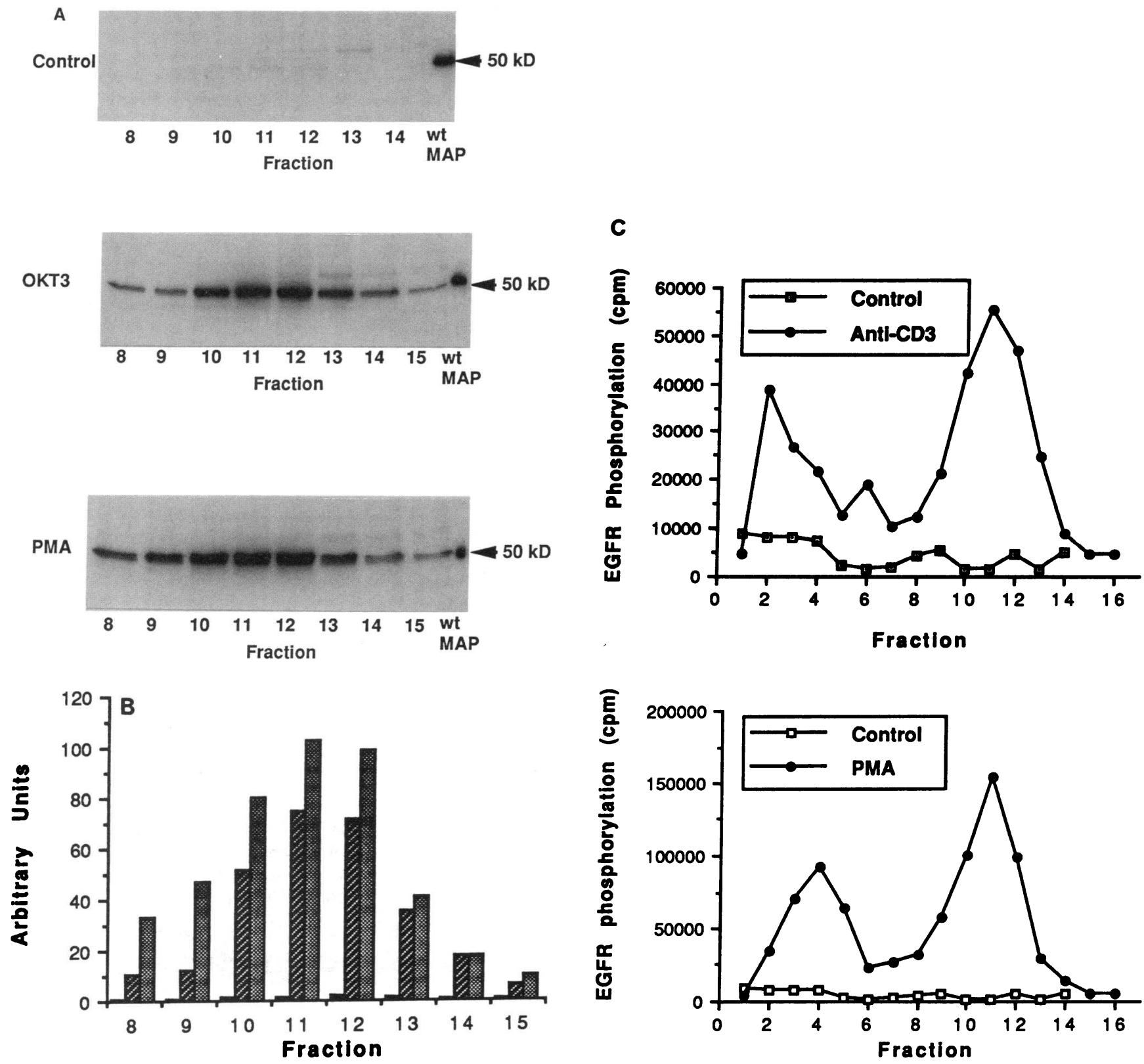

Figure 3. Anti-CD3- and PMA-induced MEK activation in Jurkat cells. For $A-C$, Jurkat cells were stimulated with $1 \mu \mathrm{g} / \mathrm{ml}$ anti-CD3 (2.5 min) or with $10 \mathrm{ng} / \mathrm{ml}$ PMA ( $10 \mathrm{~min})$ and postnuclear whole cell lysates were fractionated by mono-S chromatography. $(A)$ Fractions from the mono-S column were assayed for their ability to phosphorylate kinase-inactive recombinant MAPK and were analyzed by SDS-PAGE and autoradiography. A molecular weight standard (in $\mathrm{kD}$ ) is indicated on the right side and stimulation conditions on the left. $(B)$ Phosphorylation of kinase-inactive MAPK in the experiment described in $A$ was quantitated by phosphor-imager and arbitrary unit values are shown for each treatment group. $(C)$ In vitro kinase assays were performed on the mono-S column fractions using recombinant wild-type MAPK and EGFR $_{662-681}$ peptide. ${ }^{32} \mathrm{P}$ incorporation $(\mathrm{cpm})$ into the $\mathrm{EGFR}_{662-681}$ peptide is shown for each fraction. Representative of at least two separate experiments.

towards KMMAPK in fractions 10-12 from anti-CD3 (middle) and PMA (bottom)-stimulated Jurkat cells was greatly increased when compared with unstimulated cells (top). Quantitation of these results by the phospho-imager is shown in Fig. $3 \mathrm{~B}$. These fractions (10-12) also contain the most significant levels of immunoreactive MEK (see below).

In the indirect method, recombinant wild-type MAPK and EGFR $_{662-681}$ peptide were added to the mono-S fractions in an in vitro kinase assay. We then determined the amount of ${ }^{32} \mathrm{P}$ incorporation from ATP into the MAPK-specific EGFR $662-681$ peptide. Increases in EGFR $_{662-681}$ phosphorylation that elute off the column in the early fractions is the result of the activation of MAPK of cellular origin induced by the different treatments $(20,27)$. The increases in EGFR $662-681$ phosphorylation that elute off the column at higher salt concentrations are the result of the activation of a cellular MEK that has activated the recombinant MAPK $(20,27)$. Anti-CD3 (2.5 min) and PMA ( $10 \mathrm{~min}$ )-treated cells exhibited substantially increased MEK (fractions 9-12) as well as MAPK (fractions 2-4) activity (Fig. $3 C$, top and bottom, respectively). MEK activity was maximal 

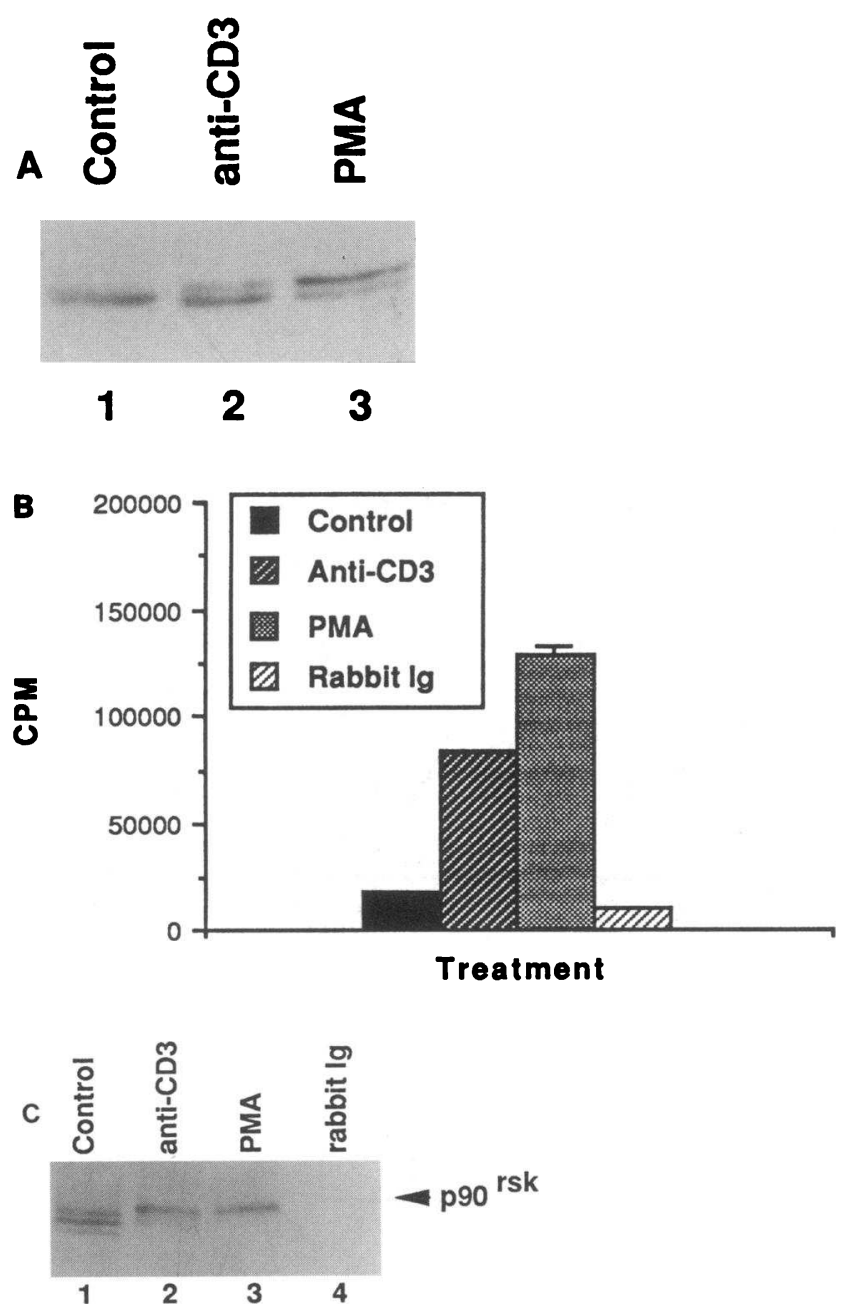

Figure 4. Activation of MAPK and $\mathrm{p} 90^{\text {rsk }}$ by anti-CD3 and PMA. In $A-C$, Jurkat cells were stimulated with either anti-CD3 $(1 \mu \mathrm{g} / \mathrm{ml}, 5$ min) or PMA ( $10 \mathrm{nM}, 15 \mathrm{~min}$ ). ( $A$ ) Postnuclear cell lysates were analyzed by SDS-PAGE and immunoblotting using an anti-MAPK antibody. $(B) \mathrm{p} 90^{\text {rak }}$ was immunoprecipitated and kinase activities of the immune complexes were measured using S6 peptide as substrate. The data are expressed as the cpm \pm standard error of ${ }^{32} \mathrm{P}$ incorporation into the $\mathrm{S} 6$ peptide. The differences from the control group were significant, $P<0.05$. $(C)$ Immunoblots of $\mathrm{p} 90^{\text {rsk }} \mathrm{im}$ munoprecipitates from cells stimulated as above. For $B$ and $C$, the lane or column marked rabbit Ig is PMA-treated samples immunoprecipitated with an equal amount of nonspecific rabbit IgG. Representative of three separate experiments.

in fraction 11 , constituting approximately 40 -fold (anti-CD3) and 120-fold (PMA) increases above levels in unstimulated cells. The identification of MEK and MAPK in these fractions was confirmed by immunoblotting (not shown). When kinase assays were performed in the presence of column buffer lacking any cellular proteins, background counts of $6,000 \mathrm{cpm}$ were detected. These values were subtracted from fractions containing cellular proteins during the calculations.

The increases in cellular MEK activity (fractions 9-12) coeluted with immunoreactive protein detected using an antibody prepared against MEK (data not shown). These data strongly suggest that the increases in MEK activity, observed after anti-CD3 or PMA stimulation, were likely due to MEK or a closely related protein. These results demonstrated for the first time the activation of MEK activity in T cells after stimulation with anti-CD3 or PMA.

When Jurkat cells were stimulated with anti-CD3 and PMA and immunoblotting was performed using a monoclonal anti-ERK 1 antibody that recognizes the $\mathrm{p} 42$ form of MAPK in our system, both anti-CD3 and PMA induced the appearance of a second, lower mobility species of MAPK (Fig. $4 A$ ). This lower mobility form of MAPK is thought to represent the activated form of this enzyme $(35,36)$. p90 ${ }^{\text {rsk }}$ is thought to be directly phosphorylated and activated by MAPK. We determined the activation status of $\mathrm{p} 90^{\text {rsk }}$ after the triggering of this Ras/Raf-1/MEK/MAPK pathway. When p90 ${ }^{\text {rsk }}$ was immunoprecipitated and the ability of these immunoprecipitates to phosphorylate the S6 peptide were monitored, significant increases were observed after either anti-CD3 (fourfold) or PMA (sevenfold) stimulation (Fig. $4 \mathrm{~B}$ ). We did not observe these increases in $\mathbf{S 6}$ kinase activity when purified mouse IgG was used to immunoprecipitate lysates from PMA-stimulated cells (Fig. $4 \mathrm{~B}$ ). To ensure that our immunoprecipitating antibody was precipitating equal amounts of $\mathrm{p} 90^{\text {rsk }}$ from each treatment group, immunoblots of the immunoprecipitates were performed using this antibody. As can be clearly seen in Fig. $4 C$, equal amounts of $\mathrm{p} 90^{\text {rsk }}$ were precipitated from all the cell treatment groups. The altered migration of $\mathrm{p} 90^{\text {rsk }}$ in these gels after stimulation with either anti-CD3 or PMA is likely due to the phosphorylation of this enzyme. These data demonstrate that the activation of MAPK and an event subsequent to MAPK activation, $\mathrm{p} 90^{\mathrm{rsk}}$ activation, occurs in Jurkat cells stimulated under conditions that lead to Ras, Raf-1, and MEK activation. (Fig. 5)

It should be noted that in the Raf/MEK/MAPK sequential phosphorylation cascade discrimination of substrates is an important regulatory mechanism. Kinases such as PKA and PKC recognize a primary consensus linear sequence in polypeptides. In contrast, Raf recognizes the native MEK protein and even

\section{T-Cell Receptor Activation of the Ras/Raf/MAPK Pathway}

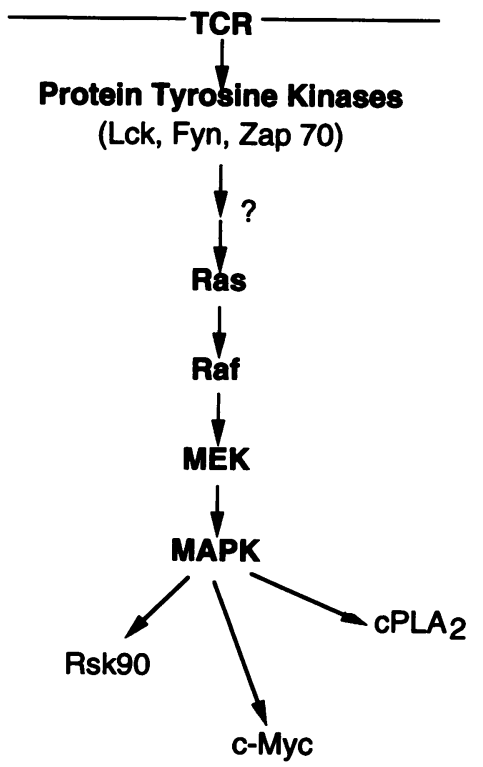

Figure 5. Schematic summarizing the proposed signaling cascade. 
mild denaturation of MEK results in loss of its phosphorylation. The phosphorylation of MAPK by MEK similarly requires a native MAPK protein. Peptides encoding sequences surrounding the tyrosine and threonine in native MAPK are not recognized by activated MEK. Thus, the conformational requirements of proteins recognized by Raf and MEK restrict the substrates recognized by the kinases in the MAPK pathway.

In Jurkat and peripheral blood lymphocytes, PKC will mediate the activation of Ras (28). Nel and coworkers (11) reported that the activation of MAPK by anti-CD3 in T cells is only partially regulated by PKC. This suggests that Ras activation is occurring via PKC-dependent and PKC-independent pathways. One possibility for the PKC-independent activation of Ras is the utilization of Vav. Vav has been shown to increase the release of guanine nucleotides, which would potentially result in the activation of Ras (37). Vav has also been shown to be activated by $\mathrm{p} 56^{\text {lck }}$, an important kinase that is associated with the T-cell receptor and is thought to be rapidly activated after receptor ligation $(37,38)$. In this pathway, stimulation of the T-cell receptor and the subsequent activation of $\mathrm{p} 56^{\text {lck }}$ could result in the activation of a Vav/Ras/Raf-1/MEK/ $\mathrm{MAPK} / \mathrm{p} 0^{\text {rsk }}$ cascade. In epithelial cells, stimulation of the EGF receptor is thought to mediate the activation of Ras via the growth factor receptor-binding protein (GRB2) and the mammalian son of sevenless gene protein ( $\mathrm{mSOS}$ ). These proteins are associated in the cytoplasm and bind to a phosphate group on the receptor $(39,40)$. This binding leads to the activation of Ras by inducing the exchange of GDP for GTP (39, 40 ). Although the role for GRB2 or mSOS in anti-CD3-induced signaling remains to be determined, it is possible that they are involved because elements in the T cell receptor complex undergo tyrosine phosphorylation after cross-linking (15). Although it is obvious from our results that activation of PKC by PMA can mediate the triggering of the Ras/Raf-1/ MEK/MAPK $/ \mathrm{p} 90^{\text {rsk }}$ cascade, we have not determined the relative contribution of a PKC-driven pathway to the other potential pathways (Vav and GRB2/mSos) leading to MAPK activation.

Recently, a novel MEK kinase has been described that is different from Raf-1 and homologous to the yeast STE 11 gene product (20). We do not know if this MEK kinase is activated in $T$ lymphocytes; it is possible that both Ras-dependent activation of Raf- 1 and the activation of MEK kinase occur after anti-CD3 and/or PMA stimulation in T lymphocytes. We do know, however, that Raf- 1 is activated and, when immunoprecipitated, it will phosphorylate MEK. MEK is also activated under these conditions, as shown by its ability to phosphorylate and activate MAPK in vitro.

Although $v$-raf is capable of inducing cellular proliferation in transfected cells (41), it is premature to conclude that this is through the activation of MAPK, because Raf- 1 may have substrates other than MEK involved in proliferative responses. Similarly, the role of MAPK activation in T cell proliferation has not been fully defined. Activated MAPK is capable of phosphorylating and activating a number of transcription factors $(23,42)$. In addition to $\mathrm{p} 90^{\text {rsk }}$, MAPK will phosphorylate transcription factors such as c-jun, c-myc, and p62 ${ }^{\mathrm{TCF}}$ in vitro (14, $15,42)$. It is likely that the cascade of Ras/Raf-1/MEK resulting in MAPK and $\mathrm{p} 90^{\text {rsk }}$ activation augments the transcription or translation of certain activation-related genes after ligation of the T-cell receptor complex.

\section{Acknowledgments}

Supported by National Institutes of Health grants R01-AI29704 (E. W. Gelfand), PO1-AI29903 (E. W. Gelfand and G. L. Johnson), and DK37871 (G. L. Johnson).

\section{References}

1. Gelfand, E. W. 1990. Cytosolic calcium changes during T and B lymphocyte activation: biological consequences and significance. In Current Topics in Membranes and Transport. Vol. 35: Mechanisms of Leukocyte Activation. S. Grinstein and O. Rotstein, editors. Academic Press, Orlando, FL. 153-177.

2. June, C. H. 1991. Signal transduction in T cells. Curr. Opin. Immunol. 3:287-293.

3. Weiss, A. 1990. Structure and function of the T cell antigen receptor. $J$. Clin. Invest. 86:1015-1022.

4. Altman, A., T. Mustelin, and K. M. Coggeshall. 1990. T lymphocyte activation: a biological model of signal transduction. Crit. Rev. Immunol. 10:347-391.

5. Weiss, A. 1993. T cell antigen receptor signal transduction: a tale of tails and cytoplasmic protein-tyrosine kinases. Cell. 73:209-212.

6. Crabtree, G. R. 1989. Contingent genetic regulatory events in T lymphocyte activation. Science (Wash. DC). 243:355-361.

7. Ullman, K. S., J. P. Northrop, C. L. Verweij, and G. R. Crabtree. 1990. Transmission of signals from the $\mathrm{T}$ lymphocyte antigen receptor to the genes responsible for cell proliferation and immune function: the missing link. Annu. Rev. Immunol. 8:421-452.

8. Hanekom, C., A. E. Nel, C. Gittenger, A. Rheeder, and G. Landreth. 1989. Complexing of the $\mathrm{CD} 3$ subunit by a monoclonal antibody activates a microtubule associated protein (MAP2-K) serine kinase in Jurkat cells. Biochem. J. 262:449-456.

9. Nel, A. E., S. Pollack, G. Landreth, J. A. Ledbetter, L. Hultin, K. Williams, R. Katz, and B. Akerley. 1990. CD3-mediated activation of MAP-2 kinase can be modified by ligation of the CD4 receptor. Evidence for tyrosine phosphorylation during activation of this kinase. J. Immunol. 145:971-979.

10. Nel, A. E., C. Hanekom, and L. Hultin. 1991. Protein kinase C plays a role in the induction of tyrosine phosphorylation of lymphoid microtubule associate protein-2 kinase. Evidence for a CD3 associated cascade that includes p56lck and is defective in HPB-ALL cells. J. Immunol. 147:1933-1939.

11. Nel, A. E., C. Hanekom, A. Rheeder, K. Williams, S. Pollack, R. Katz, and G. E. Landreth. 1990. Stimulation of MAP-2 kinase activity in T lymphocytes by anti-CD3 or anti-Ti monoclonal antibodies is partially dependent on protein kinase C. J. Immunol. 144:2683-2689.

12. Whithurst, C. E., T. G. Boulton, M. H. Cobb, and T. D. Geppert. 1992 Extracellular signal-regulated kinases in T cells. Anti-CD3 and $4 \beta$-phorbol 12 myristate 13-acetate-induced phosphorylation and activation. J. Immunol. 148:3230-3237.

13. Thomas, G. 1992. MAP kinase by any other name smells just as sweet. Cell. 68:3-6.

14. Alverez, E., E. C. Northwood, F. A. Gonzalez, D. A. Latour, A. Seth, C. Abate, T. Curran, and R. J. Davis. 1991. Pro-Leu-Ser/Thr-Pro is a consensus primary sequence for substrate protein phosphorylation. Characterization of the phosphorylation of c-myc and c-jun proteins by an epidermal growth factor receptor threonine 669 protein kinase. J. Biol. Chem. 266:15277-15285.

15. Pulverer, B. J., J. M. Kyriakis, J. Avruch, E. Nikolakaki, and J. R. Woodgett. 1991. Phosphorylation of c-jun mediated by MAP kinases. Nature (Lond.). 353:670-674.

16. Sturgill, T. W., and J. Wu. 1991. Recent progress in characterization of protein kinase cascades for phosphorylation of ribosomal protein S6. Biochem. Biophys. Acta. 1092:350-357.

17. Seger, R., N. G. Ahn, J. Posada, E. S. Munar, A. J. Jensen, J. A. Cooper, M. H. Cobb, and E. G. Krebs. 1992. Purification and characterization of mitogen-activated protein kinase activator(s) from epidermal growth factor-stimulated A431 cells. J. Biol. Chem. 267:14373-14381.

18. Ahn, N. G., R. Seger, and E. G. Krebs. 1992. The mitogen-activated protein kinase activator. Curr. Opin. Cell Biol. 4:992-999.

19. Crews, C., A. Alessandrini, and R. L. Erikson. 1992. The primary structure of MEK, a protein kinase that phosphorylates the ERK gene product. Science (Wash. DC). 258:478-480.

20. Lange-Carter, C. A., C. M. Pleiman, A. M. Gardner, K. J. Blumer, and G. L. Johnson. 1993. A divergence in the MAP kinase regulatory network defined by MEK kinase and Raf. Science (Wash. DC). 260:315-319.

21. Pelech, S. L., and J. S. Sanghera. 1992. MAP kinases: charting the regulatory pathways. Science (Wash. DC). 257:1355-1356.

22. Kyriakis, J. M., H. App, X.-F. Zhang, P. Banerjee, D. L. Brautigan, U. R. Rapp, U. R., and J. Avruch. 1992. Raf-1 activates MAP kinase-kinase. Nature (Lond.). 358:417-421.

23. Moodie, S. A., B. M. Willumsen, M. J. Weber, and A. Wolfman. 1993. 
Complexes of Ras/GTP with Raf-1 and mitogen activated protein kinase kinase. Science (Wash. DC). 260:1658-1661.

24. Vanaelst, L., M. Barr, S. Marcus, A. Polverino, and M. Wigler. 1993. Complex formation between Ras and Raf and other protein kinases. Proc. Natl. Acad. Sci. USA. 90:6213-6217.

25. Sturgill, T. W., L. B. Ray, E. Erikson, and J. L. Maller. 1988. Insulin-stimulated MAP-2 kinase phosphorylates and activates ribosomal protein S6 kinase II. Nature (Lond.). 334:715-718.

26. Gardner, A. M., C. A. Lange-Carter, R. R. Vaillancourt, and G. L. Johnson. 1994. Measuring the activation of kinases in the MAP kinase regulatory network. Methods Enzymol. In press.

27. Gardner, A. M., R. R. Vaillancourt, and G. L. Johnson. 1993. Activation of MEK (MAPK/ERK kinase) by G protein and tyrosine kinase oncoproteins. $J$. Biol. Chem. 268:17896-17901.

28. Downward, J., J. D. Graves, P. H. Warne, S. Rayter, and D. A. Cantrell. 1990. Stimulation of $\mathrm{p} 21^{\mathrm{ras}}$ upon T-cell activation. Nature (Lond.). 346:719-723.

29. Franklin, R. A., B. Mazer, H. Sawami, G. B. Mills, N. Terada, J. J. Lucas, and E. W. Gelfand. 1993. Platelet-activating factor triggers the phosphorylation and activation of MAP-2 kinase and S6 peptide kinase activity in human B cell lines. J. Immunol. 151:1802-1810.

30. Chen, R. H., and J. Blenis. 1990. Identification of Xenopus S6 protein kinase homologs ( pp90 rsk ) in somatic cells: phosphorylation and activation during initiation of cell proliferation. Mol. Cell. Biol. 10:3204-3215.

31. Terada, N., R. A. Franklin, J. J. Lucas, J. Blenis, and E. W. Gelfand. 1993. Failure of rapamycin to block proliferation once resting cells have entered the cell cycle despite inactivation of p70 S6 kinase. J. Biol. Chem. 268:12062-12068.

32. Alcorta, D. A., C. M. Crews, L. J. Sweet, L. Bankston, S. W. Jones, and R. L. Erikson. 1989. Sequence and expression of chicken and mouse $r s k$ : homologs of Xenopus laevis ribosomal S6 kinase. Mol. Cell. Biol. 9:3850-3859.
33. Siegel, J. N., R. D. Klausner, U. R. Rapp, and L. E. Samelson. 1990. T cell antigen receptor engagement stimulates c-raf phosphorylation and induces c-rafassociated kinase activity via a protein kinase C dependent pathway. J. Biol. Chem. 265:18472-18480.

34. Vojtek, A. B., S. M. Hollenberg, and J. A. Cooper. 1993. Mammalian Ras interacts directly with the serine/threonine kinase Raf. Cell. 74:205-214.

35. deVries-Smits, A. M. M., B. M. Th. Burgering, S. J. Leevers, C. J. Marshall, and J. L. Bos. 1992. Involvement of p21 ras in activation of extracellular signal-regulated kinase 2. Nature (Lond.). 357:602-604.

36. Leevers, S. J., and C. J. Marshall. 1992. Activation of extracellular signalregulated kinase, ERK2, by p21 ras oncoprotein. EMBO (Eur. Mol. Biol. Organ.) J. 11:569-574.

37. Gulbins, E., K. M. Coggeshall, G. Baier, S. Katzav, P. Burn, and A Altman. 1993. Tyrosine kinase-stimulated guanine nucleotide exchange activity of Vav in T cell activation. Science (Wash. DC). 260:822-825.

38. Straus, D., and A. Weiss. 1992. Genetic evidence for the involvement of the lck tyrosine kinase in signal transduction through the $\mathrm{T}$ cell antigen receptor. Cell. 70:585-593.

39. Marx, J. 1993. Forging a path to the nucleus. Science (Wash. DC). 260:1588-1590.

40. Chardin, P., J. H. Camonis, N. W. Gale, L. Van Aelst, J. Schlessinger, M. H. Wigler, and D. Bar-Sagi. 1993. Human Sos 1: a guanine nucleotide exchange factor for Ras that binds to GRB2. Science (Wash. DC). 260:1338-1343.

41. Smith, M. R., G. Heodecker, U. R. Rapp, and H.-F. Kung. 1990. Induction of transformation and DNA synthesis after microinjection of raf proteins. Mol. Cell. Biol. 10:3828-3833.

42. Gille, H., A. D. Sharrocks, and P. E. Shaw. 1992. Phosphorylation of transcription factor $\mathrm{p} 62^{\mathrm{TCF}}$ by MAP kinase stimulates ternary complex formation at c-fos promoter. Nature (Lond.). 358:414-417. 